\title{
Barriers and attitudes of family and internal medicine residents toward geriatric patients: a cross-sectional analytical study
}

This article was published in the following Dove Press journal:

Advances in Medical Education and Practice

\author{
Alanoud AIZamil' \\ Razan AlHoqail ${ }^{2}$ \\ Abdulaziz Alodhayani $^{2}$ \\ 'Department of Family Medicine and \\ Employee Health, King Fahad Medical \\ City, Riyadh, Kingdom of Saudi Arabia; \\ ${ }^{2}$ Department of Family Medicine and \\ Community Medicine, College of \\ Medicine, King Saud University, Riyadh, \\ Kingdom of Saudi Arabia
}

Background: In the Kingdom of Saudi Arabia, the 2016 Census indicated that there were more than 1 million people aged 65 years and older, representing $3.3 \%$ of the population. Increased life expectancy will lead to a significant increase in the elderly population in the Kingdom of Saudi Arabia by 5-fold (18\%) in 2050.

Aim: This study aimed to measure internal medicine and family medicine residents' attitudes toward elderly patients and evaluate their interest in and barriers to geriatric medicine at King Saud University Medical City.

Method: A cross-sectional observational analytical study using a convenient sampling method was performed in the internal medicine and family medicine departments at King Saud University Medical City, Riyadh, Kingdom of Saudi Arabia, from April 2017 to August 2017. The total sample size was 101 residents. Data were collected via an online survey using a predesigned validated questionnaire (University of California at Los Angeles Geriatrics Attitudes Scale).

Results: The results showed a neutral attitude of both family and internal medicine residents with $p=0.9$ and $p=0.6$, respectively, without any significant association with their training levels. Moreover, this study showed that $87 \%$ of the residents were not willing to consider geriatric medicine as a subspecialty due to the unavailability of a local geriatric training program $(59.5 \%)$, whereas the cognitive capacity of the patients was the least barrier chosen by the residents $(4.8 \%)$.

Conclusion: Based on the findings of this study, most of the participants did not receive training in geriatric medicine, which mandates the need for early exposure to geriatric training in medical schools and the need to integrate this type of training within the major postgraduate training programs of the Saudi Commission for Health Specialties .

Keywords: attitude, geriatric, residents, family medicine, internal medicine

\section{Introduction}

The 2016 Census indicated that the Kingdom of Saudi Arabia has more than 1 million people aged 65 years and older, representing $3.3 \%$ of the population. ${ }^{1}$ Increased life expectancy will lead to a significant increase in the elderly population in the Kingdom of Saudi Arabia by 5-fold (18\%) in $2050 .^{2}$ The elderly are a specialized subpopulation of the community requiring different health care needs and attention. Older people are utilizing more health care services so the need for well-trained geriatricians is increasing with time. Establishing geriatrics fellowship training programs are important to serve the community with their current and future needs for geriatricians. Well-trained geriatricians are
Correspondence: Abdulaziz Alodhayan Family and Community Medicine Department \#34, College of Medicine, King Saud University, PO Box 2925 Riyadh I I56I, Kingdom of Saudi Arabia

Tel +96 6II 4692767

Fax +966II 4671231

Email drodhayanil2@yahoo.com 
a cornerstone to provide high-quality health care services to the geriatric population that may improve their life expectancy and increase their satisfaction. Two-thirds of patients managed by family physicians are aged 65 years and older; many of these doctors received only minimal geriatrics training. ${ }^{3}$ Despite these realities, many primary care physicians do not enjoy providing care for older patients, citing the chronic, complex, and often worsening nature of medical conditions in the elderly, the need for frequent communication with family members, time pressures and the administrative burden in carrying out the work, and their perceived ineffectiveness. ${ }^{4,5}$ Medical trainees are usually not exposed to geriatric medicine training as the medical schools' curriculum in the Kingdom of Saudi Arabia and postgraduate training programs of the Saudi Commission for Health Specialties have insufficient training in this area. One of the main barriers to providing high-quality education and training in geriatric medicine to residents is a serious and growing shortage of practicing geriatricians and geriatrics faculty. ${ }^{6}$ At the postgraduate level, subspecialty training in geriatrics is required within a short period for residents who specialize in family medicine, internal medicine, and psychiatry, with training being mandatory in some specialties and elective in others. ${ }^{3}$ It is important to identify the attitudes of health care professionals toward elderly patients, especially in recognizing negative attitudes toward aging. ${ }^{7}$ Negative attitudes lead to ageism, a process of systematic stereotyping of and discrimination against people because they are old. ${ }^{8}$ Ageism generates and reinforces a fear of the aging process and legitimizes the use of chronological age to classify people who may be systematically denied resources and opportunities. ${ }^{9}$ However, negative attitudes toward aging are much less discussed and researched than the attitudes toward gender (sexism) or race (racism). ${ }^{7}$ A study by the World Health Organization of more than 83,000 people in 57 countries found that $60 \%$ of responders have little respect for older people, with negative attitudes higher in richer countries. Older people who feel they are a burden perceive their lives to be less valuable, putting them at risk of depression and social isolation. Recently published research shows that older people who hold negative views about their own aging do not recover as well from disability and live on average 7.5 years less than people with positive attitudes. ${ }^{10}$ This study aimed to measure the level of attitudes of internal medicine and family medicine residents toward geriatric patients and to identify the barriers to considering geriatric medicine as a future career. The study was conducted at King Saud University Medical City.

\section{Methods}

\section{Study design and setting}

This was a cross-sectional observational study. It was conducted in the internal medicine and family medicine departments of King Saud University Medical City, Riyadh, Kingdom of Saudi Arabia, from April 2017 to August 2017.

\section{Sampling method}

The participants were selected using a convenient sampling method.

\section{Inclusion criteria}

This study involved female and male internal medicine and family medicine residents at King Saud University Medical City. Saudi and non-Saudi citizens were also included in the study.

\section{Exclusion criteria}

Medical students, fellows, consultants, non-internal medicine and non-family medicine residents were excluded from the study.

\section{Sample size}

Using Epi Info version 7 software with a population size of 128 at 5\% confidence limits, $50 \%$ expected frequency, and a $95 \%$ confidence level, we needed 96 residents. By anticipating $10 \%$ nonresponse based on the pilot study, the sample size was increased to 106 residents.

\section{Data collection methods}

An anonymous self-administered Google online questionnaire was distributed to family and internal medicine residents via email. The questionnaire consisted of three sections.

The first section consisted of questions regarding demographic data such as age, gender, nationality, past medical school, and specialty. It also included questions regarding experiences in practicing geriatric medicine.

The second section aimed to assess the level of attitude using the 14-item University of California at Los Angeles Geriatrics Attitudes Scale (UCLA-GAS). The validity of this questionnaire was evaluated in a previous study. ${ }^{11}$ The UCLA-GAS survey is a 14-item scale was designed to assess the health care providers' attitudes toward the 
elderly and caring for geriatric patients, which matched the purpose of this study. Two questions in the original UCLA-GAS were modified to adapt the questionnaire to the local context, as described and validated in a previous study from Singapore: ${ }^{12}$ "federal government" was changed to "government" and "Medicare" changed to "care of the elderly." Two additional questions were added to the survey. These questions were adapted from Kishimoto et $\mathrm{al}^{13}$ and are: I feel comfortable working with elderly adults, and most elders feel uncomfortable discussing the issue of death and dying with their physician. ${ }^{13}$ This section consists of 6 positive and 10 negative statements about the attitude toward older adults. Responses are expressed using a 5-point bipolar Likert scale ( $1=$ strongly disagree, $2=$ somewhat disagree, $3=$ somewhat neutral, $4=$ agree, and $5=$ strongly agree).

The third section was concerned with the interest in geriatric medicine and the barriers to considering geriatric medicine as a subspecialty. This section had two questions: the first question asked about their future interest in geriatric medicine, and the second concerned those who had no interest in geriatric medicine. They were asked to choose from the 11 listed barriers, which have all been taken from a previous study, ${ }^{3}$ and one additional barrier regarding local training.

\section{Pilot study}

A pilot study was performed to verify the validity, usability, and reliability of the questionnaire. The study was conducted among 12 residents.

11 out of 12 residents filled out the form from different genders, training levels, and specialties. The participants were given 4-5 min to fill out the survey form.

Based on the feedback we received from the residents who filled out the survey form, the questions were clear and with no ambiguities except for the word "ordeal." The researchers replaced the word "ordeal" with the word "difficult" to make it more understandable.

\section{Data analysis plan}

Data were analyzed using Statistical Package for Social Science (SPSS) software version 21. Analyses included descriptive statistics (means, SDs, and frequencies); an independent $t$-test was used to compare the results, and ANOVA for comparing more than two groups. $p<0.05$ was considered statistically significant. The 10 negative statements in the UCLA-GAS were reversed ( 1 to 5,2 to 4,3 stays as 3,4 to 2 , and 5 to 1 ) before adding them to the scale. The UCLA-GAS contains 5 scores and 4 intervals for each statement; by dividing the 4 intervals over the 5 scores, the result is 0.8 . Then, 0.8 is multiplied by each total value from 16 to 80 . Each interval represents a specific category: $16-28.8$ as strongly negative, 28.8-41.6 as negative, 41.6-54.4 as neutral, 54.4-67.2 as positive, and $67.2-80$ as strongly positive.

\section{Ethical considerations}

The International Review Board of King Saud University Medical City approved the study on April 13, 2017. The questionnaire included a cover page explaining the rationale of the research; the informed consent indicates the purpose of the study, why they were chosen, all potential risks and benefits, and the participants' right to withdraw at any time without any obligations toward the study team.

\section{Results}

Table 1 shows the demographic data of the participating residents. A total number of 101 residents completed our online questionnaire: $65.3 \%(\mathrm{n}=66)$ of them were males and $34.7 \%(n=35)$ were females. Approximately $89 \%(\mathrm{n}=90)$ of the residents were graduates from King Saud University. Approximately $68.3 \%(n=69)$ of our samples were internal medicine residents and $31.7 \%$ $(\mathrm{n}=32)$ were family medicine residents, of which $57.4 \%(\mathrm{n}=58)$ were junior residents (postgraduate year

Table I Demographic data

\begin{tabular}{|c|c|c|}
\hline Variable & Level & n (\%) \\
\hline \multirow[t]{2}{*}{ Gender } & Male & $66(65.3 \%)$ \\
\hline & Female & $35(34.7 \%)$ \\
\hline \multirow[t]{2}{*}{ Age (years) } & $24-29$ & 92 (9l.I\%) \\
\hline & $30-35$ & $9(8.9 \%)$ \\
\hline \multirow[t]{2}{*}{ Nationality } & Saudi & 98 (97\%) \\
\hline & Non-Saudi & $3(3 \%)$ \\
\hline \multirow[t]{2}{*}{ Past medical school } & King Saud University & $90(89.1 \%)$ \\
\hline & Others & II (10.9\%) \\
\hline \multirow[t]{2}{*}{ Specialty } & Internal medicine & 69 (68.3\%) \\
\hline & Family medicine & $32(31.7 \%)$ \\
\hline \multirow[t]{4}{*}{ Postgraduate year (PGY) } & PGY-I & $27(26.7 \%)$ \\
\hline & PGY-2 & $31(30.7 \%)$ \\
\hline & PGY-3 & $23(22.8 \%)$ \\
\hline & PGY-4 & 20 (I9.8\%) \\
\hline
\end{tabular}


Table 2 Total attitude using the University of California at Los Angeles Geriatrics Attitudes Scale

\begin{tabular}{|l|l|l|l|l|l|}
\hline Variable & Level & $\mathbf{n}$ & Mean & SD & $\boldsymbol{p}$-value \\
\hline Gender & Male & 66 & 47.17 & 5.143 & 0.633 \\
& Female & 35 & 48.54 & 4.943 & 0.835 \\
\hline Specialty & Internal & 69 & 47.64 & 5.05 & 0.608 \\
& medicine & & & & \\
& Family & 32 & 47.66 & 5.265 & 0.931 \\
& medicine & & & & \\
\hline Postgraduate year & PGY-I & 27 & 47.44 & 5.184 & 0.998 \\
(PGY) & PGY-2 & 31 & 47.16 & 5.392 & 0.968 \\
& PGY-3 & 23 & 47.09 & 4.795 & 1.000 \\
& PGY-4 & 20 & 49.30 & 4.846 & 1.084 \\
\hline Previous training & Yes & 16 & 49.00 & 3.983 & 0.996 \\
& No & 85 & 47.39 & 5.256 & 0.570 \\
\hline
\end{tabular}

[PGY]-1 and PGY-2) and 42.6\% (n=43) were senior residents (PGY-3 and PGY-4).

Table 2 shows the attitudes of the participants toward geriatric patients. The total attitude scores of the residents toward their geriatric patients were analyzed based on their gender, specialties, postgraduate year, and previous training in geriatric medicine. About 66 were male residents and 35 were female residents, and their mean scores on the UCLAGAS were $47.17(\mathrm{SD}=5.14)$ and $48.54(\mathrm{SD}=4.94)$ out of 80 , respectively. The results suggested that these residents had neutral attitudes toward elderly patients without significant difference between the two groups. The mean scores of both internal and family medicine residents ranged from 47.64 $(\mathrm{SD}=5.05)$ to $47.66(\mathrm{SD}=5.26)$ out of 80 , suggesting that they had neutral attitudes toward the elderly patients without any significant difference between the two groups ( $p=0.6$ and $p=0.9$ ). In the postgraduate years (from PGY-1 to PGY-4), the residents had a mean score of $47-49(\mathrm{SD}=5.18-4.84)$, which is within the neutral zone, with no significant difference between them. Only 16 of the 101 participants received training in geriatric medicine and had a mean score of 49 $(\mathrm{SD}=3.98)$ out of 80 . A total of 85 residents acknowledged that they have not received any training in geriatric medicine during their residency and had a mean score of 47.3 $(\mathrm{SD}=5.25)$.

Table 3 shows the interest and barriers of the family and internal medicine residents in geriatric medicine as a subspecialty. 89 of the participants were not willing to consider geriatric medicine as a subspecialty and 13 considered geriatric medicine as a future career. The residents reported that the cognitive capacity of the patients was the least important
Table 3 Interest in geriatric medicine and barriers to considering geriatric medicine as a subspecialty

\begin{tabular}{|c|c|c|c|}
\hline \multicolumn{2}{|c|}{$\begin{array}{l}\text { Are you thinking of } \\
\text { geriatric medicine } \\
\text { as a subspecialty? }\end{array}$} & \multirow{2}{*}{$\begin{array}{l}\text { Yes, } \\
\mathrm{n}=13\end{array}$} & \multirow{2}{*}{$\begin{array}{l}\text { No, } \\
\text { n=89 } \\
\text { Family } \\
\text { medicine, } \\
\text { n (\%) }\end{array}$} \\
\hline & $\begin{array}{l}\text { Total, } \\
\text { n (\%) }\end{array}$ & & \\
\hline $\begin{array}{l}\text { Unavailability of local } \\
\text { geriatric training } \\
\text { program }\end{array}$ & $50(59.5 \%)$ & 35 (57.4\%) & 15 (65.2\%) \\
\hline $\begin{array}{l}\text { Complexity of } \\
\text { patients }\end{array}$ & 45 (53.6\%) & 31 (50.8\%) & 14 (60.9\%) \\
\hline Lifestyle issues & 21 (25\%) & 14 (23\%) & 7 (30.4\%) \\
\hline Anticipated income & $22(26.2 \%)$ & $22(36.1 \%)$ & $0(0 \%)$ \\
\hline $\begin{array}{l}\text { Nonprocedure- } \\
\text { oriented specialty }\end{array}$ & $18(21.4 \%)$ & 17 (27.9\%) & I (4.3\%) \\
\hline $\begin{array}{l}\text { Cognitive capacity of } \\
\text { patient }\end{array}$ & $4(4.8 \%)$ & $3(4.9 \%)$ & I (4.3\%) \\
\hline $\begin{array}{l}\text { Complex family social } \\
\text { issues }\end{array}$ & 31 (36.9\%) & 25 (4l\%) & $6(26.1 \%)$ \\
\hline Chronicity of disease & 48 (57.I\%) & $37(60.7 \%)$ & II (47.8\%) \\
\hline $\begin{array}{l}\text { My lack of comfort } \\
\text { with ambiguity }\end{array}$ & 15 (17.9\%) & II (I8\%) & $4(17.4 \%)$ \\
\hline $\begin{array}{l}\text { Not known as } \\
\text { a prestigious } \\
\text { discipline }\end{array}$ & 7 (8.3\%) & $6(9.8 \%)$ & I (4.3\%) \\
\hline $\begin{array}{l}\text { Focus on patients' } \\
\text { quality of life as } \\
\text { opposed to a cure }\end{array}$ & $13(15.5 \%)$ & II (I8\%) & $2(8.7 \%)$ \\
\hline Other & $4(4.8 \%)$ & $3(4.9 \%)$ & I (4.3\%) \\
\hline
\end{tabular}

among the barriers $(4.8 \%, n=4)$, while the unavailability of a local geriatric training program was the strongest barrier $(59.5 \%, \mathrm{n}=50)$. None of our family medicine residents considered the anticipated income as a barrier.

\section{Discussion}

The elderly population in the Kingdom of Saudi Arabia is estimated to increase by 5 -fold $(18 \%)$ in 2050 , which encouraged the researchers to study residents' attitudes toward geriatric patients and determine their interest in and barriers to practice in the field of geriatric medicine. The total attitude scores of the residents toward their 
geriatric patients were studied and analyzed in the present study. Generally, most studies have reported that residents show a positive attitude toward geriatric patients. ${ }^{7}$ In this study, we found that the majority of residents have neutral attitudes toward their elderly patients.

A study conducted among medical students demonstrated neutral to positive attitudes toward elderly patients; ${ }^{14}$ the same results were reported in a study conducted among first-year medical students from the National University of Singapore School of Medicine. ${ }^{12}$ Another study conducted in Singapore reported that the junior residents in a tertiary care public hospital showed an overall positive attitude toward the elderly patients, ${ }^{7}$ while the oncology health care professionals displayed negative attitudes toward the elderly patients. ${ }^{8}$ However, in this study no significant difference was observed between internal medicine, family medicine, and male or female residents.

Exposure to geriatric medicine during residency may positively influence the doctors' attitudes toward elderly patients. ${ }^{7}$ In this study, all residents displayed a neutral attitude from PGY-1 to PGY-4 without any significant differences. However, a study conducted in the USA reported that the attitudes were progressively more positive with more medical training. ${ }^{11}$ About 85 of the 101 residents in this study did not receive training in geriatric medicine. However, there was no significant difference in the attitude between residents who had the chance to receive training in the field of geriatric medicine and those who did not. On the other hand, a study investigating the effects of an educational program in geriatrics on the attitudes of a group of third-year medical students showed that the students' attitudes were significantly improved following the geriatrics training program. $^{15}$

We found that $87 \%$ of the residents were not willing to consider geriatric medicine as a subspecialty. The same was found in a study conducted in the University of North Carolina in 2008 , which reported that only $26.1 \%$ of the family medicine residents planned to provide care in nursing homes. ${ }^{5}$ A study conducted in Singapore showed that only one-third of the cohort of first-year medical students were willing to consider a career in geriatric medicine. ${ }^{12}$ However, a study in Canada revealed that less than $20 \%$ of first-year medical students were interested in geriatric medicine as a subspecialty, but the number of students decreased to $16 \%$ in second-year medical students. ${ }^{3}$ A study at the University of North Carolina found that the interns were more interested in care for the elderly than were second- and third-year residents. $^{5}$

In this study, the barriers to considering geriatric medicine as a future career were determined. We found that the main barriers among all of the residents were the unavailability of local geriatric training programs (59.5\%), while internal medicine residents consider the chronicity of disease as the main barrier $(60.7 \%)$, which was also found to be one of the major domains of difficulty reported in a US study conducted among primary care physicians. ${ }^{4}$ In this study, family medicine residents did not consider the anticipated income from practicing in the geriatrics field as a barrier. However, a study conducted at the University of North Carolina in 2008 examined the obstacles and incentives, and found that time constraints and financial concerns were often cited as obstacles to nursing home care. $^{5}$

\section{Recommendations}

We recommend repeating the study in more different specialties, involving larger sample sizes, especially with increased intention toward caring for this age group within the Kingdom of Saudi Arabia. Based on the findings of this study, almost $84 \%$ of the participants did not receive training in geriatric medicine, which mandates the need for early exposure to geriatric training in medical schools and the need to integrate this type of training within the major programs of the Saudi Commission for Health Specialties. Lack of local training in the field of geriatric medicine must be addressed and developed. The Saudi Geriatric Society should take a step forward in advocating for geriatric care among health care workers and to raise awareness of its importance.

\section{Conclusion}

In this study, we found that the residents displayed a neutral attitude toward caring for elderly, without any significant difference between internal medicine, family medicine, and male or female residents.

We found that $87 \%$ of the residents were not willing to consider geriatric medicine as a subspecialty.

The study revealed that $59 \%(n=50)$ of our residents consider the unavailability of a local geriatric training program as the main barrier to pursuing a career in geriatric medicine, and the cognitive capacity of the patients was the least barrier reported by the residents $(4.8 \%, n=4)$. 


\section{Acknowledgments}

The authors thank the Deanship of Scientific Research and Researchers Support \& Services Unit at King Saud University for their technical support.

\section{Disclosure}

The authors declare no conflicts of interest in this work.

\section{References}

1. Azalghamdi. Demographic research bulletin 2016 [Internet]. General Authority for Statistics; 2016. [cited February 2017, 4]. Available from: https://www.stats.gov.sa/sites/default/files/987goo456.jpg.

2. Saudi Arabia: proportion of elderly population between 1950. Figure 2 of 2 [Internet]. ResearchGate. [cited March 2017, 16]. Available from: https://www.researchgate.net/figure/289299253_fig2_Figure-3-SaudiArabia-proportion-of-elderly-population-between-1950-and-2050Source.

3. Diachun LL, Hillier LM, Stolee P. Interest in geriatric medicine in Canada: how can we secure a next generation of geriatricians? J Am Geriatr Soc. 2006;54(3):512-519. doi:10.1111/j.1532-5415.2005.00610.x

4. Adams WL, McIlvain HE, Lacy NL, et al. Primary care for elderly people: why do doctors find it so hard? Gerontologist. 2002;42 (6):835-842. doi:10.1093/geront/42.6.835

5. Helton MR, Pathman DE. Caring for older patients: current attitudes and future plans of family medicine residents. Fam Med. 2008;40 (10):707-714
6. English SK, van Schagen JE. Creating a geriatric medicine fellowship program in 10 "easy" steps. J Am Geriatr Soc. 2011;59 (10):1934-1940. doi:10.1111/jgs.2011.59.issue-10

7. Lui NL, Wong CH. Junior doctors' attitudes towards older adults and its correlates in a tertiary-care public hospital. Ann Acad Med Singapore. 2009;38(2):125-129.

8. Kearney N, Miller M, Paul J, Smith K. Oncology healthcare professionals' attitudes toward elderly people. Ann Oncol. 2000;11 (5):599-601. doi:10.1023/A:1008327129699

9. Bytheway B, Johnson J. On defining ageism. Crit Soc Policy. 1990;10(29):27-39. doi:10.1177/026101839001002902

10. Schlein L Study: negative attitudes toward older people shorten their lives [Internet]. Available from: https://www.voanews.com/a/negativeattitudes-toward-older-people-shorten-their-lives/3530122.html.

11. Reuben DB, Lee M, Davis JW, et al. Development and validation of a geriatrics attitudes scale for primary care residents. $J$ Am Geriatr Soc. 1998;46(11):1425-1430.

12. Chua MPW, Soiza RL. Attitudes of first year medical students in Singapore towards older people and willingness to consider a career in geriatric medicine. Ann Acad Med Singapore. 2009;38 (5):461-465.

13. Kishimoto M, Nagoshi M, Williams S, Masaki KH, Blanchette PL. Knowledge and attitudes about geriatrics of medical students, internal medicine residents, and geriatric medicine fellows. $J \mathrm{Am}$ Geriatr Soc. 2005;53(1):99-102. doi:10.1111/j.1532-5415.20 05.53018.x

14. Koh GCH, Merchant RA, Lim WS, Amin Z. The knowledge-attitude dissociation in geriatric education: can it be overcome? Ann Acad Med Singapore. 2012;41(9):383-389.

15. Warren DL, Painter A, Rudisill J. Effects of geriatric education on the attitudes of medical students. J Am Geriatr Soc. 1983;31(7):435-438.
Advances in Medical Education and Practice

\section{Publish your work in this journal}

Advances in Medical Education and Practice is an international, peerreviewed, open access journal that aims to present and publish research on Medical Education covering medical, dental, nursing and allied health care professional education. The journal covers undergraduate education, postgraduate training and continuing medical education including emerging trends and innovative models linking education, research, and health care services. The manuscript management system is completely online and includes a very quick and fair peer-review system. Visit http://www.dovepress.com/testimonials.php to read real quotes from published authors. 